\title{
EFFECT OF MONOSODIUM GLUTAMATE ON THE CEREBELLAR CORTEX OF MALE ALBINO RAT AND PROTECTIVE ROLE OF VITAMIN C
} Abd El-mawla El sayed Aidaros, Amal Al-Shahat Ibrahim, Heba Osama Mohammed, * Nancy Husseiny Hassan

Department of Human Anatomy and Embryology, Faculty of Medicine, Zagazig University, Zagazig 44519, Egypt

corresponding Author:

Nancy Husseiny Hassan nancyhusseiny@gmail.com

\begin{abstract}
Background: Monosodium Glutamate (MSG) is one of the most widely used food-additives in commercial foods that had effect on various tissues including cerebellum. It acts via creating an oxidative stress. The central nervous system is a target organ for MSG especially cerebellar cortex. The health benefits of vitamin $\mathrm{C}$ were derived from its role in the key reactions within immune function, metabolism, and other enzymatic reactions. Aim: To evaluate the effect of MSG on rat's cerebellar cortex with the possible protective role of Vitamin C. Methods: Twenty one adult male albino rats have been used in this work. The animals were randomly divided into three groups with seven animals in each group. Group 1 (Control): Animals were kept without addition of any chemicals. Group 2 (MSG-treated): Animals were subjected to administration of MSG $4 \mathrm{gg} / \mathrm{kg}$ body weight dissolved in $1 \mathrm{ml}$ normal saline. Group 3 (MSG and Vitamin C treated): Animals were subjected to administration of both MSG $4 \mathrm{~g} / \mathrm{kg}$ body weight dissolved in $1 \mathrm{ml}$ normal saline and $500 \mathrm{mg} / \mathrm{kg}$ vitamin $\mathrm{C}$, orally. By the end of the experiment which was 10 days. Animals were anaesthetized and sacrificed. Cerebellar hemispheres were obtained and specimens were processed for both light and electron microscopic examination. Results: MSG caused histopathological and morphometric changes in rat's cerebellar cortex. Vitamin C protected the cerebellar cortex specimens against such changes. Conclusion: MSG could result in hazards to the structure of cerebellar cortex. Fortunately co-administration of vitamin $\mathrm{C}$ is suggested to reduce such hazards.
\end{abstract}

Keywords: Adult rats, cerebellar cortex, monosodium glutamate, vitamin C.

\section{INTRODUCTION}

Mos ost food additives act either as preservatives or enhancer of palatability. One of such food additives is monosodium glutamate (MSG) ${ }^{(1)}$. Recently MSG is commonly sold in Egyptian markets and many Egyptians consume it almost daily ${ }^{(2)}$. The central nervous system is an important target organ for $\mathrm{MSG}(3,4)$. A previous study documented that $4 \mathrm{~g} / \mathrm{kg}$ but not $2 \mathrm{~g} / \mathrm{kg}$ MSG treatment early in life increased the brain's ability to propagate cortical spreading depression (CSD) when neonatal animals reached 45 - 60 days of age ${ }^{(5)}$. In addition, various studies reported that $2 \mathrm{~g} / \mathrm{kg}$ of MSG for 10 consecutive days initiated multiple neurotoxic pathways and affected many neurochemical parameters ${ }^{(6)}$.It has been known that MSG - induced neuronal toxicity that was mediated by oxidative stress ${ }^{(7)}$. Also the increased oxidative stress may mediate the MSG induced cerebellar injury through the depletion of glutathione which resulted in a form of cell injury called oxidative glutamate toxicity ${ }^{(8)}$.

Hashem et al. ${ }^{(9)}$ documented that MSG affects Purkinje cells of cerebellum as they appeared with darkly stained cytoplasm and shrunken darkly stained nuclei, while with vitamin $\mathrm{C}$ administration these effects were decreased.

Ascorbic acid was the antioxidant of choice as dehydroascorbic acid, the main form of oxidized vitamin $\mathrm{C}$ in the body, may reduce neurological deficits due to its ability to cross the blood brain barrier ${ }^{(10)}$. This protective role of ascorbic acid was explained by Farombi and 
Onyema (11) who mentioned that, dietary antioxidants as ascorbic acid, vitamin $\mathrm{E}$ and quercetin had protection potential against oxidative stress induced by MSG, and also by Pavlovic et al. ${ }^{(\mathbf{1 2})}$ who found that, the treatment with ascorbic acid may prevent the MSGinduced cytotoxicity in rat thymocytes by upregulating $\mathrm{Bcl}-2$ protein expression (cell lymphoma protein). The aim of this work was to elucidate the possible changes that take place in the structure of cerebellar cortex of adult male albino rats after administration of Monosodium Glutamate (MSG) and the protective effect of vitamin $\mathrm{C}$ using different histological procedures.

\section{Chemicals}

\section{MATERIAL AND METHODS}

Monosodium glutamate and vitamin C: They were obtained from Al-kahira Company of pharmaceutical industries as a powder and were dissolved in normal saline solution.

\section{Experimental animals}

The study was performed on twenty-one healthy adult male Wistar albino rats (3 months old) weighing 180-220 gm. The animals were obtained from the animal house, Faculty of Medicine, Zagazig University. The animals were housed under controlled laboratory conditions. All experimental procedures were performed in accordance with the guidelines of the Institutional Animal Care and the norms of Ethical Committee of Faculty of Medicine; Zagazig University. The rats were divided into 3 groups as follows:

First (control) group: Animals were kept without any medications.

Second (MSG-treated) group: Rats were subjected to oral administration of $\mathrm{MSG} / 4 \mathrm{~g} / \mathrm{kg}$ body weight dissolved in $1 \mathrm{ml}$ normal saline" (12).

Third (MSG and Vitamin C-treated) group: MSG $\lceil 4 \mathrm{~g} / \mathrm{kg}$ body weight dissolved in $1 \mathrm{ml}$ normal saline and $500 \mathrm{mg} / \mathrm{kg}$ vitamin $\mathrm{C}$, orally (12)

\section{Methods}

I. Experimental Methodology:

At the beginning of the study all the used rats were weighed and marked in all groups. By the end of the experiment which was 10 days, the animals were weighed again to be compared with those weights in the beginning, then anaesthetized with intra-peritoneal injection of thiopental, its heart was exposed, and saline solution was perfused through the left ventricle until the fluid comes out, from the right atrium after being opened, and was blood-free. The cranial cavity was opened; the brain was carefully dissected out and left immersed in the fixative and undisturbed for one hour then the cerebella were extracted ${ }^{(13)}$.

II. Light microscopic examination:

The fixed samples in $10 \%$ formol saline were processed and embedded on flat surface of the hemisphere in paraffin wax. Sections of $5-\mu \mathrm{m}$ thickness were obtained and prepared for the following stains:

- Hematoxylin $(\mathrm{H})$ and Eosin (E) for general structure.

- Glial fibrillary acidic protein (GFAP) for Astroglia.

Other samples were cut into small pieces $(1 \mathrm{~mm})$ and were fixed in buffered glutaraldehyde solution to be stained with toluidine blue stain.

III Electron microscopic examination:

The specimens were cut into small pieces $1 \mathrm{~mm}$ by sharp razors on a sheet of dental wax. The specimens were fixed in buffered glutaraldehyde solution. Sections were examined under JEM-2100, electron microscope unit, Mansoura University, images were captured using AMT CCD camera (software version AMTV600).

IV Statistical (morphometric) study "By image analysis" for Purkinje cell number and Thickness of molecular cell layer:

The data were obtained using computerized image' analyzer (Leica Imaging System Ltd., Cambridge, England). Cerebellar sections randomly selected for morphometric measurements. The image analyzer was first calibrated automatically to convert the measurement units (pixels) produced by the image analyzer program into actual micrometer units. Ten readings were obtained in each specimen and the mean values 
Abd El-mawla et al

were obtained. Using the interactive measure, the number of Purkinje cells and thickness of molecular cell layer were measured using magnification X 400 with measure frame $7381.11 \mu \mathrm{m}$. Data were analyzed using statistical package of Social Science (SPSS) version 20 (SPSS Inc., Chicago, Illinois, USA), then expressed by using two variants of analytic tests, Kruskal-Wallis test for comparison between more than two groups not normally distributed having quantitative variables or of relatively small sample size and One-way ANOVA (analysis of variance) for comparison of three or more independent quantitative variables normally distributed. The results were considered statistically significant at $\mathrm{P}$-value < 0.05 .

\section{Rat body weight}

\section{RESULTS}

By comparing animals' body weight at the beginning and at the end of the study for each group there was a statistical significant increase in body weight in all groups. By comparing the body weight of the three groups at the end of experiment, there was a statistical significant difference between the three groups ( $p$-value $<$ 0.001 ), as the rats receiving MSG have the highest body weight (mean body weight of 308 g), compared with control group (mean body weight of $230 \mathrm{~g})$. (Table 1)

\section{Light Microscopic Examination $H \& E$ stain}

The cerebellar cortex of control group showed that the molecular cell layer and Purkinje cell layer was arranged in one row with densely packed granular cell layer. Meningeal coverings were intact. There was a well-defined core of white matter stuffed with less packed fusiform cells. The cerebellar folia were separated by deep and long sulci (Fig.1a). The cortex showed few scattered cells in molecular cell layer, Purkinje cell layer contained Purkinje cells which were large and flask shaped arranged in one row. Densely packed granular cell layer was with small rounded granular cells (Fig.1b).The cortex of the MSG- treated group showed that there was densely packed granular cell layer. Meningeal coverings were detached.

\section{Zagazig University Medical Journals}

There was a well-defined core of white matter stuffed with less packed fusiform cells (Fig.1c).The cortex of the MSG- treated group showed Purkinje cell layer with necrotic widely spaced cells (Fig.1d). The cortex of MSG + vit. $\mathrm{C}$ treated group showed that meningeal coverings were intact and less congested. (Fig.1e).The cortex of MSG +vit.C treated group showed that the Purkinje cell layer contained some cells which were degenerated and necrotic and others were flask shaped with pale nuclei and prominent nucleoli (Fig.1f).

Immuno-histochemical results for GFAP (Glial Fibrillary Acidic Protein)

The control sections showed dense positive reaction in astrocytes which appeared large and with long, regular, linear and parallel to each other processes and glial limitans membrane was well developed (Fig. 2a). In MSG- treated group, there was marked positive reaction to GFAP in astrocytes which were large densely packed around Purkinje cells, with long and fragmented, thin and not parallel to each other processes and the cell body is more expressed with the GFAP reaction. The glial limitans membrane was separated from the cortex (Fig. 2b). In MSG +vit. C treated group, there was positive reaction to GFAP in astrocytes which were large densely packed around Purkinje cells, with long and fragmented processes. The glial limitans membrane was preserved and well developed (Fig. 2c). The mean percent of reactivity in control and $\mathrm{MSG}+\mathrm{Vit} \mathrm{C}$ groups were $7.71 \pm 2.91$ and $8.75 \pm 2.31$ respectively. One-way ANOVA revealed a statistically significant difference in immunoreactivity between all groups $[\mathrm{F}(2,12)=22.94, \mathrm{p}<0.001]$. Post hoc analyses indicated that the immunereactivity in MSG treated group was significantly higher than that in control and MSG+ vit. C treated groups respectively. However, the slight differences in immunoreactivity between control and $\mathrm{MSG}^{+}$ vit. C treated groups were statistically nonsignificant.

\section{Toluidine Blue stain}

In control group, Purkinje cells were arranged in one row and appeared large flask-shaped, 


\section{Abd El-mawla et al}

near Purkinje cells there were astrocytes (Fig. 3a). In MSG- treated group, the cerebellar cortex was infiltrated with astrocytes which were presented mostly adjacent to Purkinje cells which were shrunken, distorted and deeply stained. Granular layer contained some cells preserving their normal appearance and others were distorted with necrotic nuclei (Fig. 3b).In MSG + vit.C treated group, some Purkinje cells were shrunken, distorted and deeply stained; others were flask-shaped with pale nuclei and prominent nucleoli. Most of granular cells were keeping their rounded or oval nuclei; others were deeply stained and distorted (Fig. 3c).

\section{Electron Microscopic Finding}

The cerebellar cortex of control group showed granule cells which had oval or rounded nuclei with coarse central and peripheral chromatin clumps and scanty cytoplasm containing mitochondria. The surrounding neuropil contained myelinated nerve fibers (Fig.4a). The control groups also showed Purkinje cell which was large flask shaped with euchromatic nucleus with indentations, prominent nucleolus and cytoplasm containing mitochondria and free ribosomes (Fig.5a). The astrocyte also appeared with sharply demarcated nucleus and electron lucent cytoplasm containing mitochondria. The astrocytes were present near the blood capillary which was lined by endothelial cells. The surrounding neuropil contained myelinated nerve fibers. Oligodendrocyte had irregular deeply stained nuclei (Fig.6a).

The cerebellar cortex of MSG- treated group showed granular layer with granular cell containing rounded or oval nuclei with clumped chromatin, vacuoles in cytoplasm and necrotic fragmented cells with intact cell membrane. The surrounding neuropil contained distorted myelinated nerve fibers (Fig.4b). Purkinje cell

\section{Zagazig University Medical Journals}

appeared with euchromatic nucleus with prominent nucleolus; its cytoplasm contained marked dilated rough endoplasmic reticulum and mitochondria. There was also an astrocyte with sharp demarcated nucleus with vacuolated cytoplasm and mitochondria (Fig.5b). The surrounding neuropil contained unmyelinated nerve fibers and granule cells. Purkinje cell was presented with its distinguished damaged appearance (Fig.6b).

The cerebellar cortex of MSG +vit.C treated group showed granule cells which had rounded or oval nuclei with clumped chromatin, vacuoles in cytoplasm which also contained mitochondria (Fig.4c). Purkinje cell contained euchromatic irregular nucleus and prominent nucleolus with indentations all around illdefined nuclear membrane and its cytoplasm was dark, contained mitochondria, strands of mildly dilated rough endoplasmic reticulum and free ribosomes (Fig.5c). The astrocytes appeared with sharp demarcated nucleus with chromatin and vacuolated cytoplasm containing mitochondria and few vacuoles (Fig.6c).

\section{Morphometric Results}

There was statistical significant difference between the three groups as regard the number of Purkinje cells (p-value $<0.001$ ), as the rats receiving MSG have the lowest number of Purkinje cells (mean number of 2.1 cells), compared with control group (mean number of 6.1 cells) (Table.2).

There was statistical significant difference between the three groups as regard the thickness of molecular cell layer ( $\mathrm{p}$-value = 0.008 ), as the controlled rats have the thickest molecular cell layer (mean thickness of 145.5 um), compared with MSG- treated group (mean thickness of $114.3 \mathrm{um}$ ) (Table.3). 

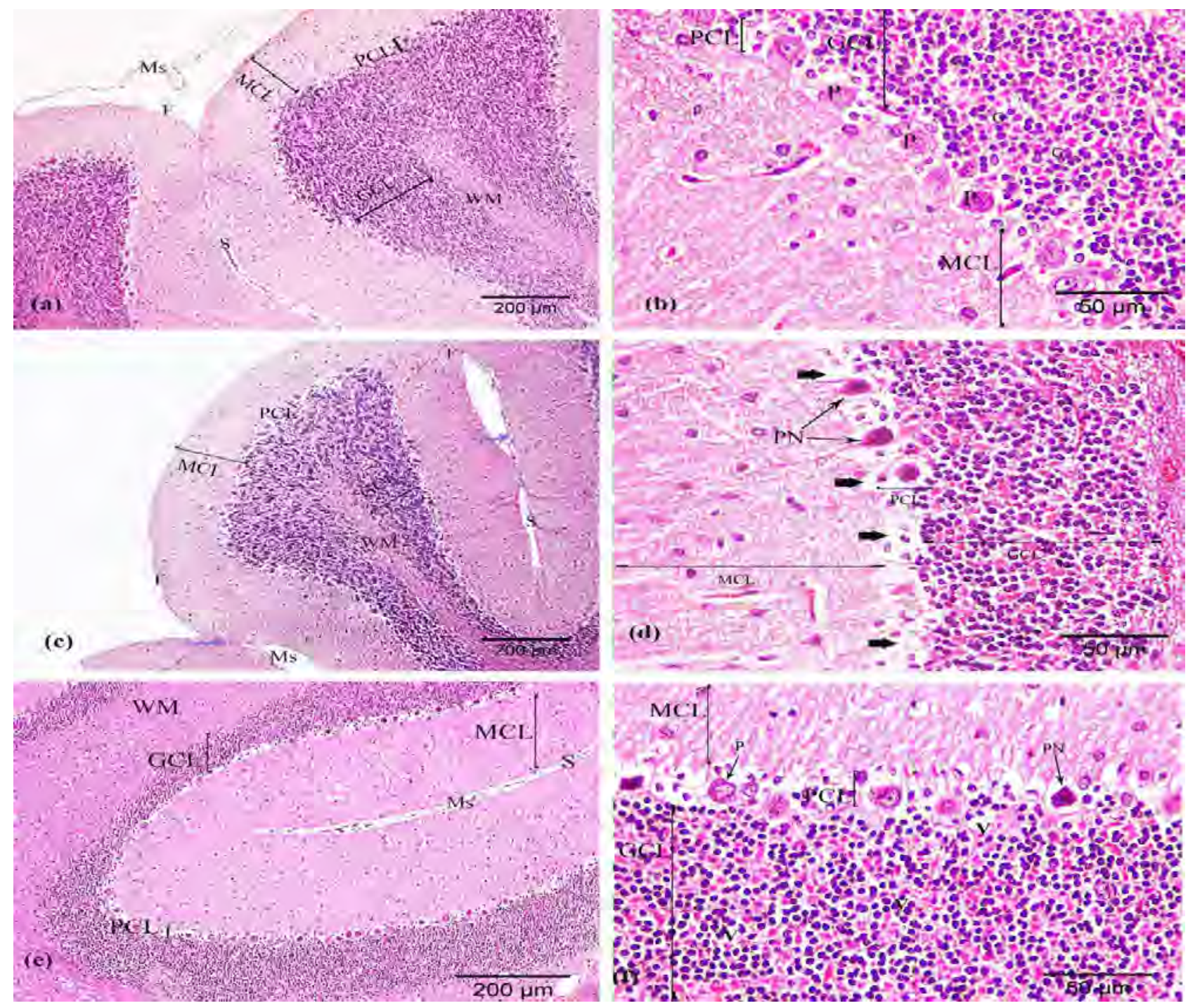

Fig. 1: Photomicrographs of cerebellar cortex of the different groups: a) Control group showing: Molecular cell layer (MCL), Purkinje cell layer (PCL) arranged in one row and densely packed granular cell layer (GCL). Meningeal coverings are intact (Ms). There is a well-defined core of white matter (WM) stuffed with less packed fusiform cells. The cerebellar folia (F) are separated by deep and long sulci (S). b) Molecular cell layer (MCL), Purkinje cell layer (PCL) Purkinje cells (P) which are large flask in shape arranged in one row. Densely packed granular cell layer (GCL) with small rounded granular cells (G) are also observed in granular layer.c) molecular cell layer (MCL), Purkinje cell layer (PCL) arranged in one row. Densely packed granular cell layer (GCL). Meningeal coverings (Ms) are detached (zigzag blue arrows). There is a well-defined core of white matter (WM) stuffed with less packed fusiform cells. The cerebellar folia (F) are separated by sulci (S). d) Molecular cell layer (MCL), Purkinje cell layer (PCL) contains necrotic cells (PN) with spacing between cells (thick arrows), vacuolated granular layer (GCL) appear. e) Molecular cell layer (MCL), Purkinje cell layer (PCL) are arranged in one row. Densely packed granular cell layer (GCL). Meningeal coverings (Ms) are intact and less congested. There is a well-defined core of white matter (WM) stuffed with less packed fusiform cells. The cerebellar folia are separated by sulci (S). f) Molecular cell layer (MCL), some Purkinje cell layer (PCL) containing some cells which are degenerated and necrotic (PN) and others are normal (P), vacuolated (V) granular layer (GCL) appear. [a, c \& e: H\&E X 100; b, d \&f: H\&E X400[ 
Abd El-mawla et al

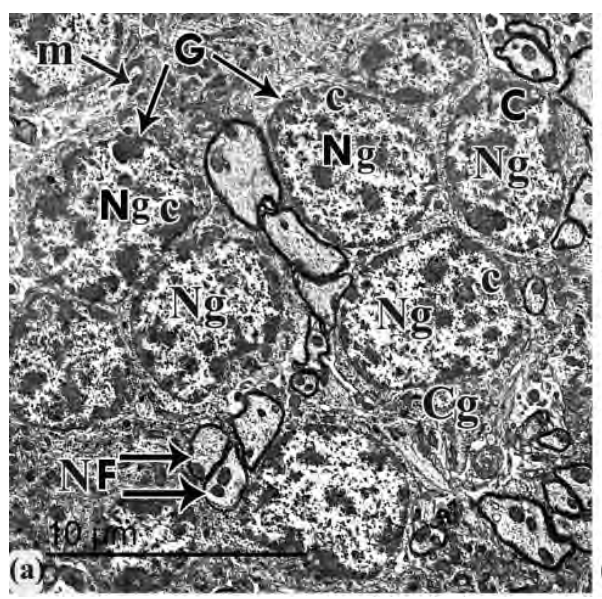

Fig. 4: a) A photomicrograph of transmission electron microscope of cerebellar cortex of adult control albino rat shows granule cells $(\mathbf{G})$ which have oval or rounded nuclei $(\mathbf{N g})$ with coarse central and peripheral chromatin clumps $(\mathbf{C})$, scanty cytoplasm $(\mathbf{C g})$ containing mitochondria $(\mathbf{m})$. The surrounding neuropil contains myelinated nerve fibers $(\mathbf{N F})$. $($ TEM $\times \mathbf{8 0 0} \times \mathbf{1 7})$ b) A photomicrograph of transmission electron microscope of cerebellar cortex treated group shows granular layer with granular cells $(\mathbf{G})$ containing rounded or oval nuclei $(\mathbf{N g})$ with clumped chromatin $(\mathbf{c})$, vacuoles $(\mathbf{V})$ in cytoplasm $(\mathbf{C g})$, necrotic fragmented cells $(\mathbf{K})$ with intact cell membrane. The surrounding neuropil contains distorted myelinated nerve fibers $(\mathbf{N F})($ TEM $\times \mathbf{8 0 0} \times \mathbf{1 7}) \mathbf{C}) \mathrm{A}$ photomicrograph of transmission electron microscope of cerebellar cortex of protected group shows Granule cells $(\mathbf{G})$ which have rounded or oval nuclei $(\mathbf{N g})$ with clumped chromatin $(\mathbf{c})$, vacuoles in cytoplasm $(\mathbf{C g})$ which also contains mitochondria $(\mathbf{m}) .($ TEM $\times 1500 \times 17)$
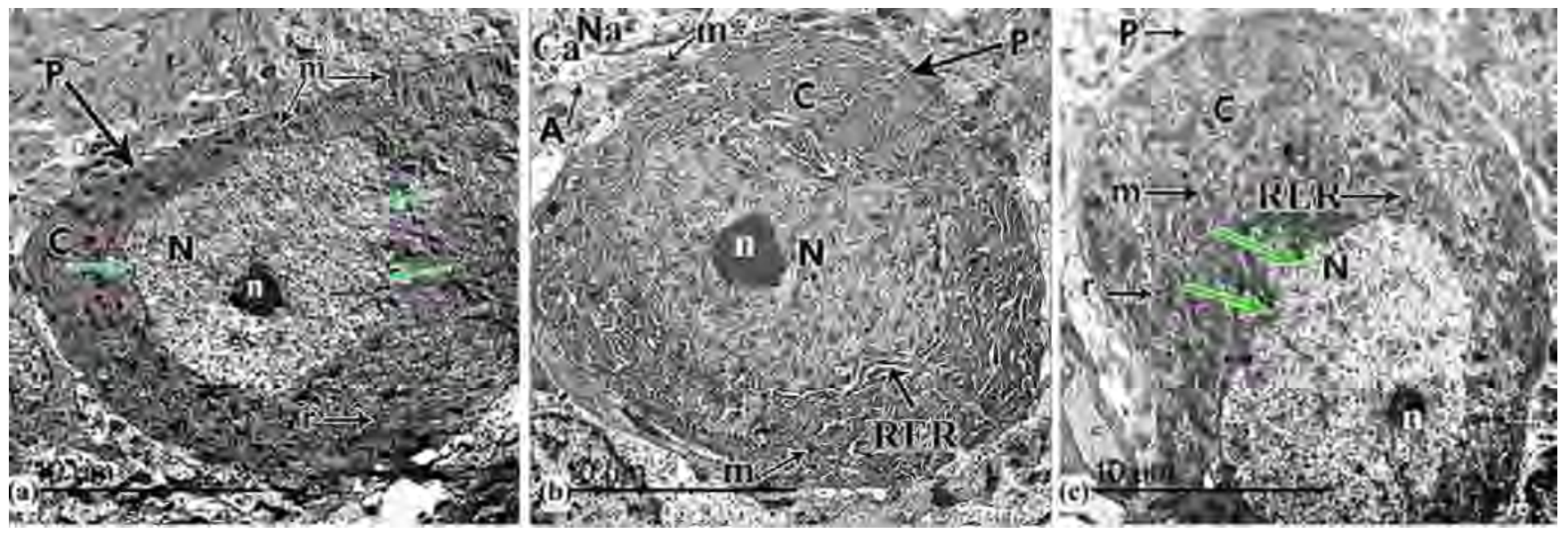

Fig. 5: a) A photomicrograph of transmission electron microscope of cerebellar cortex of adult control albino rat showing a Purkinje cell (P) which is large flask shaped with euchromatic nucleus $(\mathbf{N})$ with indentations (green arrows), prominent nucleolus (n) and cytoplasm (C) containing mitochondria (m) and free ribosomes (r). (TEM $\times \mathbf{8 0 0} \times \mathbf{1 7})$ b) A photomicrograph of transmission electron microscope of cerebellar cortex treated adult albino rat shows Purkinje cell (P) with euchromatic nucleus (N) with prominent nucleolus (n); its cytoplasm (C) contains marked dilated rough endoplasmic reticulum (RER) and mitochondria with destructed cristae $\left(\mathbf{m}^{*}\right)$.An astrocyte (A) with sharp demarcated nucleus (Na) with vacuolated cytoplasm (Ca) and mitochondria (m) (TEM $\times \mathbf{8 0 0} \times \mathbf{1 7})$. c) A photomicrograph of transmission electron microscope of cerebellar cortex of protected adult albino rat shows Purkinje cell (P) contains euchromatic irregular nucleus (N) and prominent nucleolus (n) with indentations all around ill-defined nuclear membrane (arrows) and its cytoplasm (C) is dark, containing mitochondria $(\mathbf{m})$, strands of mildly dilated rough endoplasmic reticulum (RER) and free ribosomes (r) (TEM $\times$ 800 $\times 17)$. 

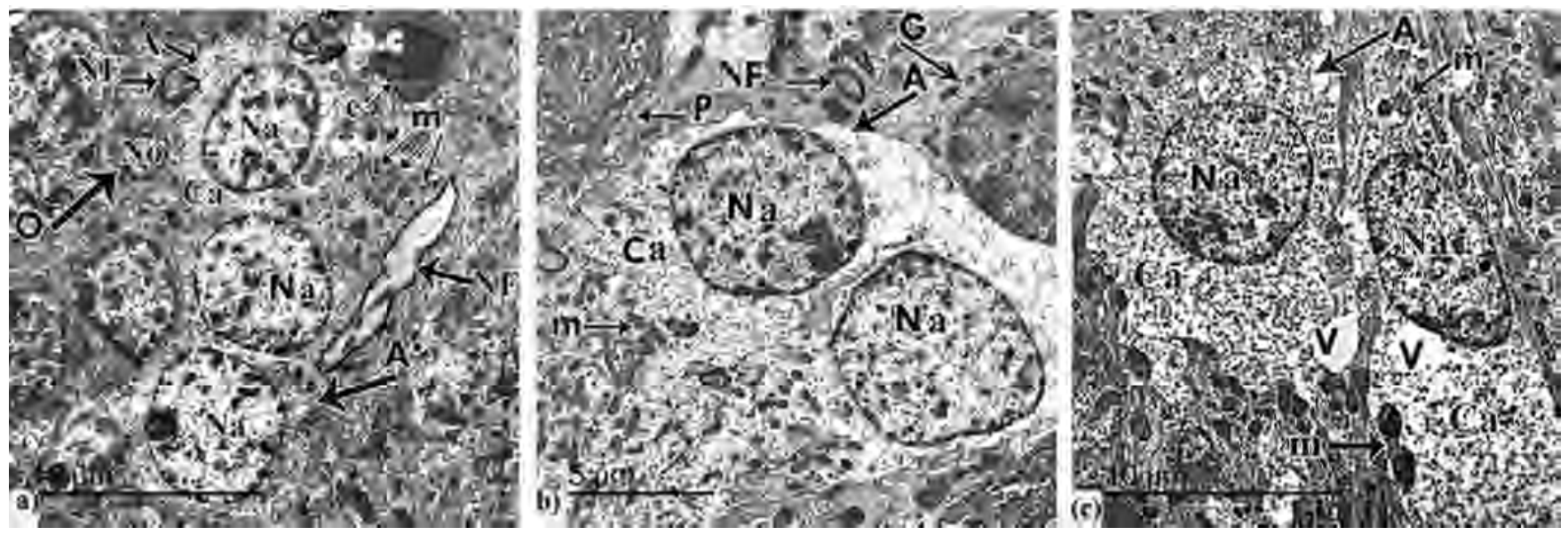

Fig. 6 a) A photomicrograph of transmission electron microscope of a section of cerebellar cortex of adult control albino rat shows an astrocyte (A) with sharply demarcated nucleus (Na) and electron lucent cytoplasm (Ca) containing mitochondria (m). The astrocytes are present near the blood capillary (b.c) which is lined by endothelial cells (e). The surrounding neuropil contains myelinated nerve fibers (NF). Oligodendrocyte (O) has irregular deeply stained nuclei $(\mathbf{N o}) .($ TEM $\times \mathbf{8 0 0} \times \mathbf{1 7})$ b) A photomicrograph of transmission electron microscope of a section of cerebellar cortex treated adult albino rat shows astrocytes (A) with sharp demarcated nucleus (Na) with chromatin and vacuolated cytoplasm (Ca) which contains mitochondria (m*). The surrounding neuropil contains unmyelinated nerve Fibers (NF) and granule cell (G). Purkinje cell (P) appears with its distinguished damaged appearance. $($ TEM $\times 1000 \times 17)$ c) A photomicrograph of transmission electron microscope of a section of cerebellar cortex of protected adult albino rat shows astrocytes (A) with sharp demarcated nucleus (Na) with chromatin (blue arrows) and vacuolated cytoplasm (Ca) containing mitochondria (m) and few vacuoles $(\mathbf{V})$. $($ TEM $\times \mathbf{8 0 0} \times \mathbf{1 7})$

Table 1 Comparison between body weights of group 1 (control), group 2 (MSG- treated) and group 3 (MSG + vit C treated).

\begin{tabular}{|c|c|c|c|c|}
\hline \multirow[t]{2}{*}{ Group } & \multicolumn{2}{|c|}{$\begin{array}{l}\text { Final body weight at the end of experiment } \\
\text { (g) }\end{array}$} & \multicolumn{2}{|c|}{$\begin{array}{l}\text { One-way } \\
\text { ANOVA }\end{array}$} \\
\hline & Range & Mean \pm SD & $\mathbf{F}$ & P-value \\
\hline Control & $210-270$ & $230.33 \pm 15.98$ & \multirow{3}{*}{57.229} & \multirow{3}{*}{$0.0008^{*}$} \\
\hline $\begin{array}{c}\text { MSG+ vit C } \\
\text { treated }\end{array}$ & $230-255$ & $244.00 \pm 9.62$ & & \\
\hline MSG treated & $295-320$ & $308.00 \pm 10.37$ & & \\
\hline
\end{tabular}

Table 2 Comparison between number of Purkinje cells of group 1 (control), group 2 (MSG- treated) and group 3 (MSG + vit C treated).

\begin{tabular}{|c|c|c|c|}
\hline Group & $\begin{array}{l}\text { No. of Purkinje cells } \\
\text { (Mean } \pm 2 \text { SD) }\end{array}$ & Kruskal-Wallis test & P-value \\
\hline MSG Treated & $2.1 \pm 1.29$ & \multirow{3}{*}{15.661} & \multirow{3}{*}{$0.000 *$} \\
\hline $\begin{array}{l}\text { MSG+ Vit. C } \\
\text { Treated }\end{array}$ & $4.8 \pm 1.87$ & & \\
\hline Control & $6.1 \pm 2.33$ & & \\
\hline
\end{tabular}


Table 3 Comparison between Molecular cell layer thickness of group 1 (control), group 2 (MSGtreated) and group 3 (MSG +vitC treated).

\begin{tabular}{|l|c|c|c|}
\hline Group (adult) & \multicolumn{1}{|c|}{ Mean \pm SD } & \multicolumn{2}{c|}{ One-way ANOVA } \\
& \multicolumn{1}{|c|}{5.737} & \multirow{2}{*}{$0.008^{*}$} \\
\hline $\begin{array}{l}\text { MSG treated } \\
\text { treated vit C }\end{array}$ & $114.3 \pm 19.9$ & & \\
\hline Control & $145.5 \pm 24.5$ & & \\
\hline
\end{tabular}

\section{DISCUSSION}

The present study demonstrated that there was a significant increase of the rats' weight from the beginning to the end of the study which may be caused by the fact that MSG increases appetite, and this is in agreement with El-Helbawy et al. (14) who documented that the effects of MSG evaluated after a period of 14 days' treatment in young rats showed a statistically highly significant increase $(\mathrm{P}<0.001)$ in the mean body weight of rats compared with controls. Another study also was in agreement with current one, demonstrating that low and high doses of MSG treatment increases body weight ${ }^{(15)}$.

The present study clarified that, the molecular cell layer appeared as a zone lying superficial to Purkinje cell layer. The findings of the present study were in agreement with Young and Heath (16) who conveyed that, the mature cerebellar cortex consisted of three layers.

The current study demonstrated that, in control group the Purkinje cells were oval or flaskshaped with big rounded nuclei and prominent nucleoli with the granular cell layer with its distinguished rounded cells. These findings were in agreement with Hashem et al. ${ }^{(9)}$.

With exposure to MSG, the present work elucidated degenerative effects in the form of necrotic Purkinje cells with statistically significant decrease in its number with spacing in between mostly due to edema which was observed on the rat cerebellar cortex. This was in line with Espinar (17) and Eweka and Om'Iniabohs ${ }^{(18)}$.

In addition, Ureña-Guerrero et al. (19) found that, MSG produces neuro- degeneration with severe damaging of the cells in several brain regions when it was administered to neonatal rats, from an early embryonic age to adulthood. These toxic effects have been explained by Pavlovic et al. ${ }^{(20)}$ who mentioned that intake of high concentrations of MSG induced oxidative stress in many organs. All these findings were in agreement with present results. On contrary with Jinap and Hajeb ${ }^{\text {(21) }}$ who mentioned that, the Joint Expert Committee on Food Additives of the United Nations Food and Agriculture Organization and World Health Organization sited MSG in the safest class for food additives. The immune-histochemical studies of control all groups of the current study revealed presence of a positive reaction of glial fibrillary acidic protein (GFAP). The foot processes of astrocytes are thin, short and run in parallel rows in the molecular layer, as Hashish ${ }^{(22)}$ had reported.

In MSG- treated group astrocytes which appeared larger than that in control ones with longer irregular processes across the cerebellar cortex, and this was in agreement with Espinar (17).

As regarding the $\mathrm{MSG}+$ vit. $\mathrm{C}$ treated group, there was an improvement in all layers of the cortex which appeared in the form, Purkinje cells were mostly keeping their normal appearance with few necrotic cells with less spacing comparing to the MSG- treated group. This was confirmed by a highly statistically significant increase in number of Purkinje cells of the MSG +vit.C treated group in comparison with MSG- treated group with $\mathrm{p}$ value $<0.0000$ as mentioned by Narayanan et al. (23) and Huang et al. (24).

The GFAP immune-expression of the present study showed increase in group receiving vitamin $\mathrm{C}$, when compared with other groups 


\section{Abd El-mawla et al}

which was accompanied with preservation of the neurons in the form of long more parallel processes of astrocytes but still are irregular; this was as Hanbury et al. ${ }^{(25)}$ and Hughes et al. (26) documented.

As regarding the ultrastructural results of electron microscopy of the present study, in the control group; the granular layer contained numerous granular cells having rounded or oval nuclei with peripheral or central condensation of chromatin, their thin cytoplasm contains free ribosomes and mitochondria, as documented in previous two studies ${ }^{(13 ; 27)}$.

The present results revealed that Purkinje cells were fusiform in shape, they contained euchromatic irregular nuclei with prominent nucleolus and their cytoplasm is dark, contains few mitochondria and strands of rough endoplasmic reticulum. This was in agreement with EL Tantawi and El Namshan ${ }^{(28)}$.

The cerebellar cortex of animals treated with MSG showed the nuclei of many Purkinje and granule cells appeared shrunken and densely stained with irregular nuclear envelopes; this was in agreement with other related studies ${ }^{\mathbf{( 2 9} \text {; }}$ 30;31)

Ultra-structural observations on vitamin $\mathrm{C}$ use showed that most of the granule and Purkinje cells were remarkably healthy while few ones exhibited scarcely degenerative features. The improving effects of vitamin $\mathrm{C}$ may be attributed to its antioxidant constituents which increases the circulating level of antioxidants leading to decreasing the oxidative stress induced by MSG. This was in line with Farombi et al. ${ }^{\text {(11). }}$

\section{Conclusion}

In conclusion, MSG has toxic effect not only on nerve cells but also on astrocytes, which were reported to protect nerve cells from toxic insults, and hence came the dangerous neurotoxic effect of MSG. Vitamin C supplementation could protect from neurotoxic effect of MSG

\section{Acknowledgements}

The authors are grateful to all members of the family members of Human Anatomy and

\section{Zagazig University Medical Journals}

Embryology Department, for their kind cooperation

Conflict of Interest: Non declared. Funding: No funding sources

\section{REFERENCES}

1. Moore KL. Congenital malformation due to environmental factors. Developing humans. W.B. Saunders. Ltd. Philadelphia, 2003; 2: 173183.

2. Mohamed IK. The effects of oral dosage of monosodium glutamate applied for short- and long-terms on the histology and ultrastructure of testes of the adult rats. J. Anim, 2012 Vet. Adv, 11(1): 124- 133.

3. Gill SS, Mueller RW, McGuire PF, Pulido OM. Potential target sites in peripheral tissues for excitatory neurotransmission and excitotoxicity. Toxicol. Pathol, 2000; 28(2): 277284.

4. Mattson MP. Glutamate and neurotrophic factors in neuronal plasticity and disease. Ann N Y Acad Sci, 2008; 1144:97-112.

5. Lima CB, Soares Gde S, Vitor SM, Castellano B, Andrade da Costa BL, Guedes RC. Neonatal treatment with monosodium glutamate lasting facilities spreading depression in the cortex. Life Sci., 2013; 93(9-11): 388-392.

6. Dief AE, Kamha ES, Baraka AM, Elshorbagy AK. Monosodium glutamate neurotoxicity increases beta amyloid in the rathippocampus: A potential role for cyclic AMP protein kinase. Neurotoxicology, 2014; 42: 76 - 82.

7. Park E, Yu KH, Kim do K, Kim S, Sapkota K, et al. Protective effects of $\mathrm{N}$ - acetylcysteine against monosodium glutamate- induced astrocytic cell death. Food Chem. Toxicol., 2014; 67: 1-9.

8. Shih AY, Erb H, Sun X, Toda S, Kalivas PW, et al. Cystine/glutamate exchange modulates glutathione supply for neuroprotection from oxidative stress and cell proliferation. J Neurosci, 2006; 26: 10514-10523.

9. Hashem H, Safwat M, Algaidi S. The effect of monosodium glutamate on the cerebellar cortex of male albino rats and the protective role of vitamin $\mathrm{C}$ (histological and immunehistochemical study). J MolHist, 2012; 43: 179186.

10.Huang J, Agus DB, Winfree CJ, Kiss S, Mack WJ, McTaggart RA et al. Dehydroascorbic acid, a blood-brain barrier transportable form of vitamin $\mathrm{C}$, mediates potent cerebro-protection in 
experimental stroke". Proceedings of the National Academy of Sciences, 2001; 98 (20): P. 11720-11724.

11.Farombi EO, Onyema OO. Monosodium glutamate- induced oxidative damage and genotoxicity in the rat: modulatory role of vitamin $\mathrm{C}$, vitamin $\mathrm{E}$ and quercetin. Human \& Experimental Toxicology, 2006; 25: 251-259.

12.Pavlovic V, Pavlovic D, Kocic G, Sokolovic D, Sarac M, Jovic Z. Ascorbic acid modulates monosodium glutamate induced cytotoxicity in rat thymus. Bratisl Med J, 2009; 110(4): 205-9.

13. Mohamed HM, Mohamed HA, Abd-elhakim AH. Effects of Paracetamol and Monosodium Glutamate on Cerebellar Granule Cells of the Adult Male Albino Rats: A Histological and Morphometric Study Med. J. Cairo Univ., 2014; Vol. 82, No. 2, March: 289-302, 2014www.medicaljournalofcairouniversity.net

14.El-Helbawy N, Radwan D, Salem M, El-Sawaf M. Effect of monosodium glutamate on body weight and the histological structure of the zona fasciculata of the adrenal cortex in young male albino rats. Tanta Medical Journal, 2017; 45, 104-113.

15. Sreejesh PG, Sreekumaran E. Effect of monosodium glutamate on striato-hippocampal acetylcholinesterase level in the brain of male Wistar albino rats and its implications on learning and memory during aging. Biosci. Biotech. Res. Comm. 2018; 11(1): 76-82

16. Young B, Heath JW. Cerebellum. In: Alan, S.;Lowe, J. S.; and Deakin, P. K. eds. Functional Histology. 4ed. Chirchill livingst. One, New York, London, Philadelphia, Sydney, Toronto, PP, 2001; 376- 366.

17.Espinar A. Neuroprotection by melatonin from glutamate-induced exocitoxicity during development of the cerebellum in the chick embryo: J. pineal Res, 2000; 2: 818.

18.Eweka AO, Om'Iniabohs FAE. Histological studies of the effects of monosodium glutamate on the cerebellum of adult wistar rats. Internet $\mathrm{J}$ Neurol 8. 2007.

19.Ureña-Guerrero ME, López-Pérez SJ, and BeasZárate C. Neonatal monosodium glutamate treatment modifies glutamic acid decarboxylase activity during rat brain postnatal development. Neurochem Int. 2003; 42(4): 269-276, indexed in Pubmed: 12470699

20.Pavlovic V, Pavlovic, D, Kocic G, Sociologic D, Jevtovic-Stoimenov T, Cekic S. Effect of monosodium glutamate on oxidative stress and apoptosis in rat thymus. Mol Cell Biochem. 2007; 303(1-2):161-166.

21.Jinap S, Hajeb P. Glutamate Food Safety Research (CEFSR), Faculty of Food Science and Technology, Universiti Putra Malaysia, 2010; 43400 UPM, Serdang, Selangor, Malaysia.

22.Hashish HA Alteration of Glial Fibrillary Acidic Protein Immunoreactivity in Astrocytes of the Cerebellum of Diabetic Rats and Potential Effect of Insulin and Ginger; Anat Physiol 2015, 5:1 DOI: 10.4172/2161-0940.1000167.

23. Narayanan SN, Kumar RS, Paval J, Nayak S. Effect of ascorbic acid on the monosodium glutamate induced neurobehavioral changes in peri-aldolescent rats. India. 2010; 111(5): 247252.

24.Huang J, Agus DB, Winfree CJ, Kiss S, Mack WJ, McTaggart R. Dehydroascorbic acid, a blood-brain barrier transportable form of vitamin $\mathrm{C}$, mediates potent cerebro-protection in experimental stroke". Proceedings of the National Academy of Sciences, 2001; 98 (20): P. 11720-11724.

25.Hanbury R, Ling ZD, Wuu J, Jeffrey K. GFAP knockout mice have increased levels of GDNF that protect striatal neurons from metabolic and excitotoxic insults. J Comp Neurol., 2003 461:307-316

26. Hughes EG, Maguire JL, McMinn MT, Scholz RE, Sutherland ML. Loss of glial fibrillary acidic protein results in decreased glutamate transport and inhibition of PKA-induced EAAT2 cell surface trafficking. Brain Res Mol Brain Res., 2004 124:114-123

27. Mahran HA, Arisha SM. The ameliorative effects of the aqueous extract of rosemary against monosodium glutamate neurotoxicity in adult male albino rats: histological, ultrastructural and biochemical studies. Ejpmr, 2018; 5(1), 79-90

28.EL Tantawi HG, EL Namshan MM. Monosodium glutamate followed by barley in mice: a histological, immunohistological and ultrastructural approach. Egypt. J. Exp. Biol. (Zool.), 2015; 11(1): 81 - 93.

29. Mattson MP. Glutamate and neurotrophic factors in neuronal plasticity and disease. Ann N Y Acad Sci, 2008; 1144:97-112.

30.Afifi OK. Effect of sodium fluoride on the cerebellar cortex of adult albino rats and the possible protective role of vitamin B6: a light and electron microscopic study. Egypt. J. Histol., 2009; 32(2): 358 - 367. 8 


\section{Abd El-mawla et al}

31. Laag EM, Abd Elaziz HO. Effect of aflatoxin-B1 on rat cerebellar cortex: light and
Zagazig University Medical Journals

electron microscopic study. Egypt J. Histol., 2013 36: 601-610

How to cite this article:Abd El-mawla EA, Amal AI, Heba OM, Nancy HH.Effect of monosodium glutamate on the cerebellar cortex of male albino rat and protective role of vitamin c.ZUMJ 2019; 25 (2); 250-260.DOI: 10.21608/ZUMJ .2019.27410 